\title{
LABORATORY INVESTIGATION AND EFFICIENCY OF DEICING MATERIALS USED IN ROAD MAINTENANCE
}

\author{
Andrius Ružinskas ${ }^{1}$, Matas Bulevičius ${ }^{2}$, Henrikas Sivilevičius ${ }^{3}$ \\ ${ }^{1,3}$ Dept of Transport Technological Equipment, Vilnius Gediminas Technical University, Vilnius, Lithuania \\ ${ }^{2}$ JSC 'Problematika', Vilnius, Lithuania
}

Submitted 1 July 2015; resubmitted 4 November 2015, 29 December 2015; accepted 31 December 2015

\begin{abstract}
Snow and ice cause considerable traffic problems on roads and streets in the winter period. Timely and effective removal of these problems can prevent major car accidents. This paper presents an analysis of the efficiency of Deicing Materials (DMs) used by the Lithuanian road maintenance agencies. Five different DMs were studied by performing ice melting tests in the laboratory. DMs were evenly spread on the formed ice samples taking the same amount of grains of uniform size. The ice mass dissolved by each DM was determined at different durations of melting action, ranging from 4 to $120 \mathrm{~min}$, and at different ambient temperatures, ranging from -20 to $-3{ }^{\circ} \mathrm{C}$. The obtained results of each DM were analysed, and all the tested materials were compared under different temperature conditions. In addition, the deicing speed of each DM was calculated, and the DM was categorized according to the efficiency performance. A comparison of tested DM efficiencies was carried out, and the price of one percent of melted ice was determined.
\end{abstract}

Keywords: ice melting; deicing material; deicer performance; sodium chloride; road maintenance.

\section{Introduction}

Winter climate of Lithuania is quite complicated. It causes a lot of problems for drivers and winter road maintenance agencies. Freezing rain, ice and snow have a negative influence on road pavement and consequences of these phenomena must be eliminated as soon as possible (Ružinskas, Sivilevičius 2014).

At present, most researches on deicing chemicals are concerned with developing environmentallyfriendly chemicals, specific influence mechanisms on infrastructures, roads, bridges and environment (Dai et al. 2012). Agencies are constantly seeking alternative deicers that maximize the benefits of acetates and agrobased products while minimizing their drawbacks (Fay, Shi 2012, 2011). However, chloride-based products are widely applied for anti-icing, deicing, and pre-wetting operations, all of which lead to substantial safety, mobility and other benefits to road users, maintenance agencies and society. Traditionally, nominal cost and effectiveness are the major criteria for highway professionals selecting the chemicals for snow and ice control (Shi et al. 2013b).

Solid salt $(\mathrm{NaCl})$ is used most frequently, followed by abrasives, then magnesium chloride $\left(\mathrm{MgCl}_{2}\right)$, agriculturally based (deicers must contain some quantity of bio-based product, for example, corn or sugar beet coproducts and may also contain chlorides, acetates, and/ or formates), calcium chloride $\left(\mathrm{CaCl}_{2}\right)$ and the other deicers (Shi et al. 2009). Sodium chloride solution has a large weakening effect on snow that is compacted, even though it does not melt the snow. Snow hardness drops to $60 \%$ of the hardness of dry snow and with increasing content, the hardness gradually decreases until saturation, at which point the hardness is approximately a fifth of that of dry snow (Wåhlin et al. 2014). Sodium chloridebased anti-icing filler considerably delays the formation of ice on the pavement surface, helps in accelerating the ice-melting process and reduces the adhesion between ice and pavement (Giuliani et al. 2012).

Compared with traditional methods for snow and ice control, anti-icing and pre-wetting lead to decreased applications of chemical products, reduced abrasives, decreased maintenance costs, improved roadway friction, and lower accident rates (Shi, O’Keefe 2006). Prewetting was found to slightly decrease the melting performance of salt at relatively warm temperatures $\left(-1\right.$ and $\left.-5^{\circ} \mathrm{C}\right)$, so melting performance of dry salt appears to be improved by prewetting more at colder temperatures than warmer ones (Luker et al. 2004). Prewetted salt is retained on

Corresponding author: Andrius Ružinskas

E-mail: andrius.ruzinskas@vgtu.lt 
dry roads better than dry salt because there is a tendency for most of the small salt grains to be dissolved before they are blown off the road (Burtwell 2004). Laboratory and field experiments demonstrated that the antiicing chemicals, when properly applied, interrupted the bond between compacted snow and pavement, but differences between individual chemicals were often less apparent (Cuelho, Harwood 2012). Besides depressing the freezing point, anti-icing chemicals also control the mechanical properties of the ice that is formed when a wet pavement freezes. The presence of salt weakens the ice that forms and with sufficient salt present, it will not withstand the mechanical load exerted by the traffic (Klein-Paste, Wåhlin 2013). Anti-icing is a proven method of efficiently and effectively maintaining roadways. However, maintenance divisions must identify priority routes, prepare equipment and personnel, and apply an appropriate chemical using an accurate forecast to implement anti-icing strategies effectively (Cuelho, Harwood 2012).

Akin and Shi (2012) performed four laboratory tests:

- a Differential Scanning Calorimetry (DSC) thermogram test;

- a modified Strategic Highway Research Program (SHRP) ice melting test;

- a modified SHRP ice penetration test;

- a modified ice undercutting test.

According to the results, $\mathrm{CaCl}_{2}$ and $\mathrm{MgCl}_{2}$ are more effective deicers than $\mathrm{NaCl}$. As a liquid, $\mathrm{MgCl}_{2}$ slightly out-performed $\mathrm{CaCl}_{2}$, but the modified SHRP ice melting test showed that solid $\mathrm{CaCl}_{2}$ performed better than $\mathrm{MgCl}_{2}$. The SHRP H-205.1 standard ice-melting capacity test can be inaccurate when using standard experimental conditions suggested. The precision and accuracy can be significantly improved by using higher application rates and longer measurement times than those suggested in the original standard (Koefod et al. 2012). A DSC thermogram test showed that the potassium acetate (KAc-based) deicer had the coldest effective temperature, followed by the $\mathrm{MgCl}_{2}$-based deicer. The tribometer test revealed that the agro-based deicer led to the lowest friction coefficient on both the ice and the deiced concrete, whereas the NaCl-based solid deicer had the greatest variance of friction coefficients on the ice (Fay, Shi 2012). The freezing temperatures of $\mathrm{CaCl}_{2}, \mathrm{MgCl}_{2}, \mathrm{NaCl}$ and Calcium Magnesium Acetate (CMA) decrease as the concentrations of these Deicing Materials (DMs) increase (Mauritis et al. 1995). It should also be noted, that, for example, when $\mathrm{NaCl}$ is applied on the ice, sufficient time (e.g. $60 \mathrm{~min}$ ) should be allowed in order to achieve its full potential (Shi et al. 2013a).

Compared to solid salt, brine was found to be more effective when the mass amount of salt $(\mathrm{NaCl})$ used was considered in test sites treated by solid salt and brine under similar winter events (Hossain et al. 2014). In practise, spreading of saturated brine takes effect immediately if there is frost or ice on the road, whereas dry or prewetted salt takes time to become effective (Fonnesbech 2001).
Talking about organic materials, salts of levulinic acid had significantly different freezing points at different solution concentrations and also worked well during snow melting tests. When the temperature dropped to $-6.7^{\circ} \mathrm{C}$, sodium levulinate was effective in melting the ice while magnesium and calcium levulinate were not effective; however, at $-1.1^{\circ} \mathrm{C}$, all three salts worked well (Ganjyal et al. 2007). Organic materials are generally more expensive than regular brine but can reduce the amount of chlorides released into the environment. In addition, organic materials showed better performance in comparison to salt brine. In some cases, performance differences of over 30\% were observed (Fu et al. 2012).

Brines, solid salts and sand-salt mixtures are integral components of the highway winter maintenance toolbox, and they are best suitable for different application scenarios. For instance, for anti-icing on the relatively warm pavement, $\mathrm{NaCl}$ brine is likely to be the best product to use; yet $\mathrm{MgCl}_{2}$ brine would be a better choice to use for cold pavements, such as $-12.2^{\circ} \mathrm{C}$ or lower. For deicing, the choice between brines, solid salts, and sand-salt mixtures will hinge on how quickly one has to achieve a relatively bare pavement under the existing amount of snow accumulation and whether or not a temporary traction layer is needed on the pavement (Shi et al. 2014).

The aim of this paper is to evaluate the effectiveness of DM used in Lithuania developing a technique for a laboratory ice melting test based on SHRP H-205.1 standard. The following test can measure the ice melting capability of different products under a wide range of temperature (Nixon et al. 2005).

\section{Process of Ice Melting}

It is well known that ice melts at $0{ }^{\circ} \mathrm{C}$, and when this phenomenon occurs, ice turns from a solid to a liquid (water). Ice transition from a solid to a liquid is an endothermic process, and it requires $334 \mathrm{~kJ}$ of heat to melt $1 \mathrm{~kg}$ of ice. The ice layer on the road surface consists of water, ice, salt and some impurities. According to Fujimoto et al. (2014), the mass per unit area of this layer can be expressed by the formula:

$$
M_{\text {ice_layer }}=M_{W}+M_{i}+M_{S},
$$

where: $M_{\text {ice }}$ layer - the mass per unit area of the ice layer on the road $\left[\mathrm{kg} / \mathrm{m}^{2}\right] ; M_{W}-$ the mass of water $\left[\mathrm{kg} / \mathrm{m}^{2}\right]$; $M_{i}$ - the mass of ice $\left[\mathrm{kg} / \mathrm{m}^{2}\right] ; M_{S}$ - the mass of salt $\left[\mathrm{kg} / \mathrm{m}^{2}\right] . M_{S}$ consists of the mass of solid-phase salt $\left[\mathrm{kg} / \mathrm{m}^{2}\right]$ and the mass of liquid-phase salt $\left[\mathrm{kg} / \mathrm{m}^{2}\right]$ dissolved in solvents.

If we have adiabatic melting of ice (ideal case, when there is no heat flow from the environment), the mass of melted ice can be calculated by the formula (Klein-Paste, Potapova 2014):

$$
m_{\text {melt }}=\frac{Q_{\text {melt }}}{L}
$$

where: $m_{\text {melt }}$ - the mass of melted ice [kg]; $Q_{\text {melt }}$ - the amount of heat that is available to melt a fraction of 
the ice [J]; $L$ - the latent heat of fusion for ice $(334 \mathrm{~kJ} /$ $\mathrm{kg}$ ). Under real life conditions, there is never a situation when there is no heat flow from the environment. However, this situation can be created in the laboratory by performing the deicing in a well-insulated container. In that case, the amount of heat that is needed to melt a fraction of the ice $Q_{\text {melt }}$ can be calculated by the formula:

$$
Q_{\text {melt }}=Q_{\text {ice_cool }}+Q_{\text {sol_cool }}+Q_{\text {cont_cool }}+Q_{\text {surr }} \text {, }
$$

where: $Q_{\text {ice_cool }}$ - heat amount of decrease in temperature of the remaining ice [J]; $Q_{\text {sol_cool }}$ - heat amount of solution [J]; $Q_{\text {cont_cool }}$ - heat amount of container [J]; $Q_{\text {surr }}$ - heat amount that leaks into the container [J].

The investigation of ice and snow melting and removing from the road pavement helps to distinguish three main groups of factors (Fig. 1). Natural factors, which include climate and weather conditions: ambient temperature, the intensity of solar radiation, cloudiness, humidity and wind speed. The road surface temperature, which directly depends on the previously mentioned factors, also has a considerable influence. Chemical factors include deicing and ice-removing chemicals. The efficiency of this group depends on the type of DM (physical and chemical properties of the material), the amount of material spread on the surface of the ice and the duration of DM melting action. Artificial factors associated with snow and ice removal from the road include traffic intensity and traffic flow composition, mechanical removal of ice from the road using snow and ice removal equipment (snow clearing machine) and artificial road pavement heating.

It was also noticed that thermal physical properties of ice and snow are related to the ambient conditions. The density and porosity of snow and ice usually tend to be decreasing and increasing, respectively, as the ambient temperature decreases (Wang et al. 2008).

Usually, all DMs work in the same way. They depress the freezing point of ice or snow and turn the mixture into a liquid or slush. Solid chemical salts bore

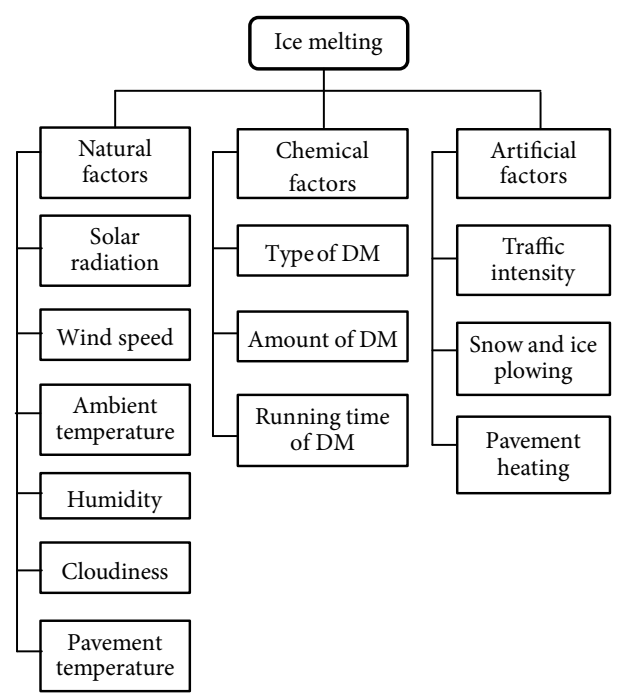

Fig. 1. Factors affecting ice melting and removing from the road through ice or snow and form a strong brine solution. This brine spreads under the ice and undercuts, breaking the bond to the surface. Once loose, the ice or snow is easily removed by mechanical means. In addition, the investigation of exchange rates of water molecules between ice and the liquid phase reveals that melting of ice by salts occurs in two stages. At short times, the melting starts by the inhibition of the association of water molecules to the crystal, while the melting is accelerated by the increased dissociation of water molecules from the crystal surface at longer times. It is also shown that $\mathrm{Cl}^{-}$ions penetrate more deeply into the ice than $\mathrm{Na}^{+}$ions while ice melts (Kim, Yethiraj 2008). The ice-melting process, when it is affected by a $\mathrm{DM}$, can be divided into four zones (Fig. 2a). The first zone is an initial intensive melting process when a DM is spread on the ice and it starts rapidly melting. The first drops of melted ice and DM solvent appear, and ice from a solid state begins turn into water. A decrease in temperature of ice surface is usually noticed during this melting period (Fig. 2b). A sudden decrease in temperature of the ice surface, when it is affected by a $\mathrm{DM}$, depends on the environmental temperature and chemical properties of materials. The DM interface must become colder than the environment to allow heat to flow toward the melting front. In addition, some deicers, such as $\mathrm{CaCl}_{2}$, release heat when dissolving, but this amount is not enough for melting. The temperature of the resulting solvent will decrease until the balance of the system is reached (Fig. 2b, point two): the number of freezing melted ice (water) molecules becomes equal to the number of melting ice molecules. The second zone is a low melting process when ice melting is rapidly
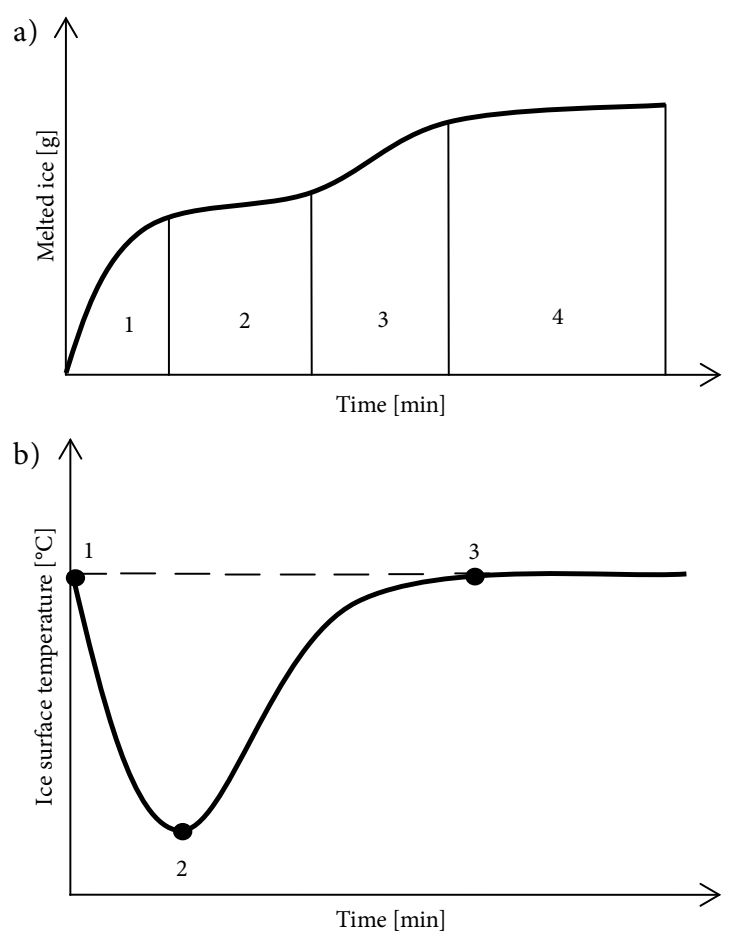

Fig. 2. Ice melting process when a DM is applied: a - ice melting zones; $\mathrm{b}$ - change of ice surface temperature 
reducing or not taking place at all. This phenomenon will continue until the temperature of ice reaches the ambient temperature (Fig. 2b, point three). The third zone is an average melting process. The intensity of ice melting increases due to the increased release of the number of melted ice (water) molecules. Typically, the melting intensity will increase until a DM dissolves the entire ice layer or until the DM melts away completely. Then, the melting process enters the fourth zone. The ice does not melt completely due to the exhaustion of DM melting resources.

A certain amount of a DM is needed to dissolve a certain amount of ice at a specified temperature. When an insufficient amount of salt is spread on the road surface covered with ice, the layer of ice does not always melt away. When the excessive amount of a DM is spread over a square meter, the entire ice melts, but in this case, some part of the DM is wasted unnecessarily, which is an economic loss.

Though common DMs work in the same way, they vary widely in performance. The determining factors are speed, required quantity of material, and the duration of melting action. Environmental considerations are also important.

\section{Methodology of the Laboratory Experiment}

The purpose of the laboratory experiment was to investigate the performance of deicing chemicals, used by agencies of Lithuanian road maintenance under different temperatures and different durations of melting action. Tests were conducted to study five different materials: $\mathrm{NaCl}, \mathrm{CaCl}_{2}, \mathrm{MgCl}_{2}$, a mixture of Sodium (75\%) and Calcium (25\%) Modified Chlorides (SCMC) and a mixture of Sodium Acetate and Sodium Formate (SASF).

A laboratory research was conducted to determine the percentage of mass lost when DM is applied. Ice samples were prepared of uniform thickness $(3 \mathrm{~mm})$ and surface area $\left(887 \mathrm{~cm}^{2}\right)$. The same amount of water (approx. $266 \mathrm{~g}$ ) was poured into the uniform stainless steel trays $30 \times 30 \mathrm{~cm}$ (Fig. 3). The water was frozen and kept in a climatic chamber until the temperature of ice surface reached the indicated temperature (from -20 up to $-3{ }^{\circ} \mathrm{C}$ ). The mass of dry trays was determined. When ice formed, trays were weighed again with the accuracy to $0.1 \mathrm{~g}$ and the mass of ice was calculated.

The trays with ice samples were kept in a climatic chamber until the temperature of ice surface reached the indicated test value. The efficiency of DMs was assessed at five different temperatures: $-20,-15,-9,-6$ and $-3{ }^{\circ} \mathrm{C}$.

In order to ensure the same test conditions for all DMs, each DM was sieved through $1 \mathrm{~mm}$ and $0.5 \mathrm{~mm}$ mesh screens. The particles that passed through $1 \mathrm{~mm}$ and retained on $0.5 \mathrm{~mm}$ sieve were used for testing. When the required temperature was reached, the same amount of the DM of about $10 \mathrm{~g}$ and of uniform size (fraction $0.5 / 1 \mathrm{~mm}$ ) was manually spread on the surface of ice sample. Then, the DM was manually spread out evenly across the entire surface of the ice sample. Ice samples with DMs spread on top were kept in a climatic

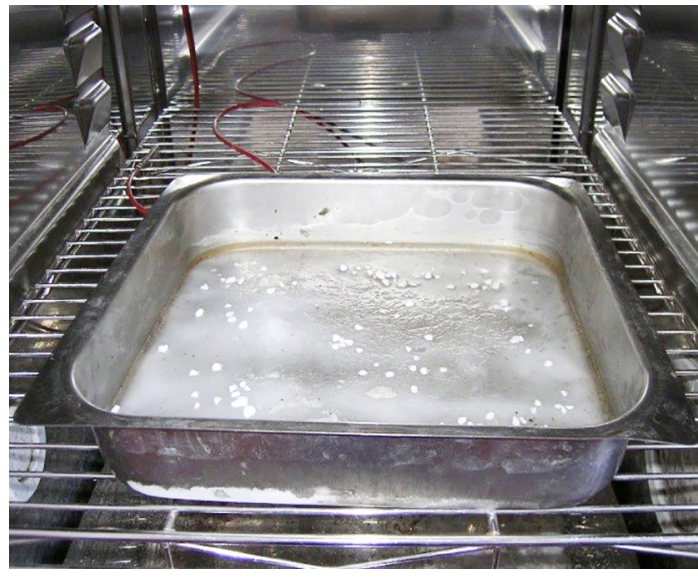

Fig. 3. Formed ice sample with an applied DM

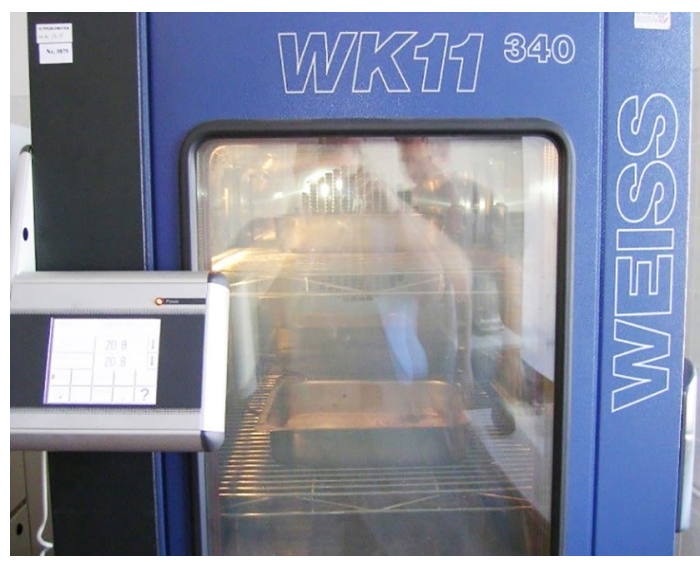

Fig. 4. Climatic chamber, where the sample was kept at different temperatures

chamber (Fig. 4) at different pre-set lengths of time. In order to accurately assess the deicing efficiency of a DM, the following durations of melting action were taken: 4 , $10,20,30,60$ and $120 \mathrm{~min}$. The samples stayed in the climatic chamber for the required time. Then, trays were removed from the chamber and immediately weighed with the accuracy of $0.1 \mathrm{~g}$. The melted ice and the DM solvent were poured off ( $10 \mathrm{~s}$ were given for drops to drip down), and the remaining ice with the DM were weighed. The number of samples was always the same in the climatic chamber during the experiment, and relative air humidity was quite close to the environmental at the same temperature.

After the performance of each test, the percentage change in mass (Ice Mass Loss - IML) of melted ice and reduced mass of ice was calculated by the formula:

$$
I M L=\frac{M_{B}-M_{A}}{M_{B}} \cdot 100,
$$

where: $M_{B}$ - ice mass before a DM is applied [g]; $M_{A}$ ice mass after the DM is applied [g]. Three tests were carried out for each DM at different temperatures and different durations of melting action. In total, 450 samples were tested $(5 \mathrm{DMs} \times 5$ temperatures $\times 6$ durations of melting action $\times 3$ repeat tests). 


\section{Influence of Temperature and the Duration of Melting Action on the Amount of Melted Ice}

IML was calculated for each tested material at different temperatures and different durations of melting action. All the results obtained from tests are presented in graphs (Fig. 5).

Laboratory test results obtained for each DM (indicated by points in Fig. 5) were approximated by the second degree of polynomial equation:

$$
I M L=A+B \cdot t+C \cdot T+D \cdot t^{2}+E \cdot T^{2}+F \cdot t \cdot T
$$

where: $A, B, C, D, E, F$ - regression coefficients; $t$ - duration of DM melting action [min]; $T$ - temperature of melted ice $\left[{ }^{\circ} \mathrm{C}\right]$. The coefficient of determination $R^{2}$, varying from 0.877 up to 0.91 , calculated for the resulting equations shows a strong correlation between variables and function.

a)

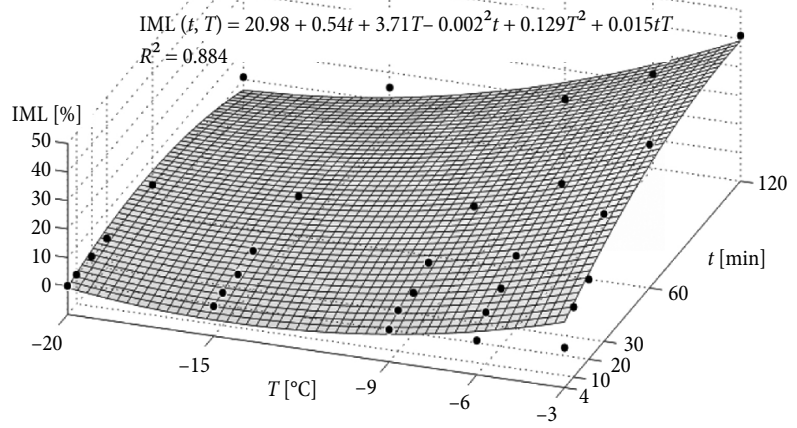

c)

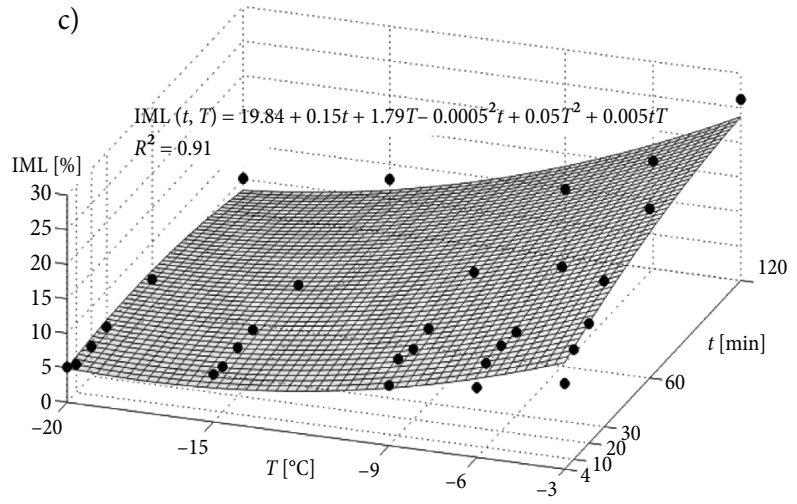

Based on the graphs, all tested DMs dissolved the largest percentage of ice mass when taking the longest duration of melting action (120 min) after spreading $\mathrm{DMs}$, and these values were reached at the highest test temperature $\left(-3{ }^{\circ} \mathrm{C}\right)$. A decrease in temperature led to a decrease in the percentage of melted ice mass. $\mathrm{NaCl}$ dissolved the largest percentage of ice mass (40.9\%) at the temperature of $-3^{\circ} \mathrm{C}$ and took the longest duration of melting action (120 min). However, at the temperature of $-20^{\circ} \mathrm{C}$, this material practically did not dissolve the ice, and the percentage change was below $1 \%$. Other DMs behaved in a similar way: the maximum IML value for $\mathrm{CaCl}_{2}$ was $33.2 \%$, and the minimum value $(3.8 \%)$ was reached at the temperature of $-3{ }^{\circ} \mathrm{C}$, 4 min after spreading the material. The maximum IML value for $\mathrm{MgCl}_{2}$ was $26.2 \%$, and the minimum value (4.1\%) was reached $10 \mathrm{~min}$ after spreading the material.

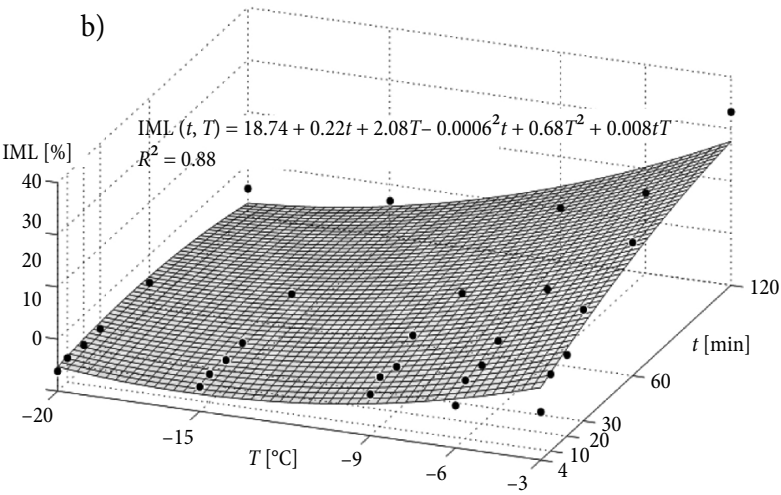

d)

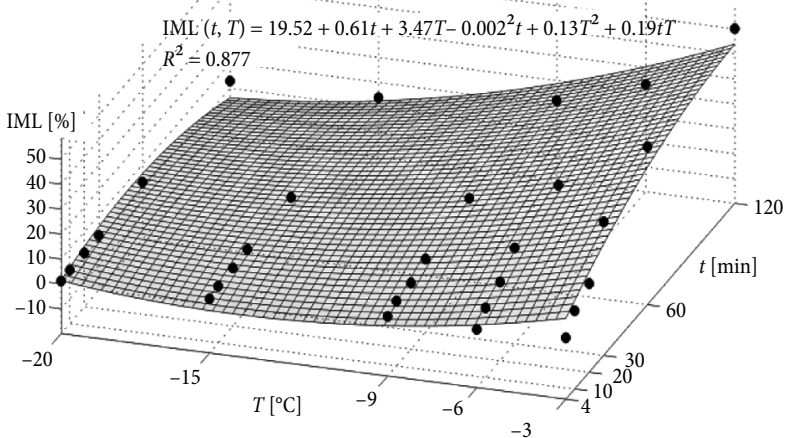

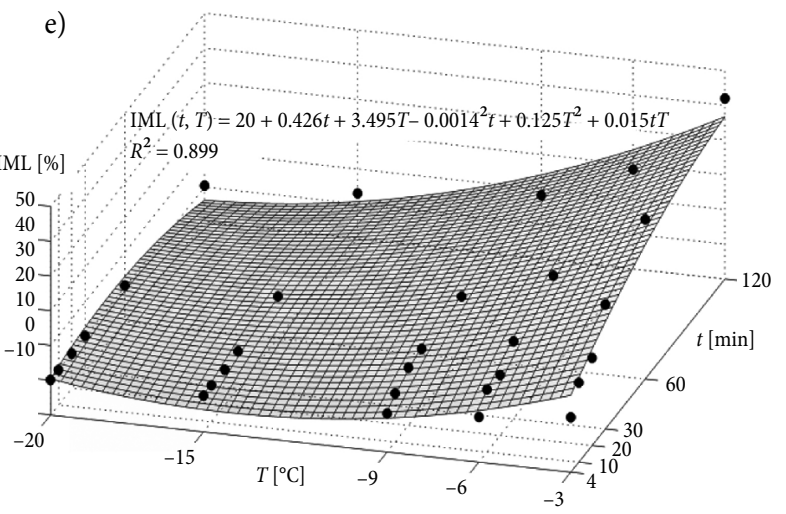

Fig. 5. Influence of temperature and duration of melting action on the IML, when DM is applied: a - NaCl; b - $\mathrm{CaCl}_{2} ; \mathrm{c}-\mathrm{MgCl}_{2} ; \mathrm{d}-\mathrm{SCMC}$; - SASF 
The maximum value of SASF was $41.9 \%$, and the minimum value was also reached at the temperature of $-20^{\circ} \mathrm{C}$; however, it did not exceed even $0.5 \%$. Of all the tested DMs, SCMC dissolved the largest percentage of ice mass - approximately $50 \%$; however, the minimum IML value $(1.1 \%)$ was reached at the temperature of $-20^{\circ} \mathrm{C}$, 4 min after spreading the material. The following part of this work focuses on the study of the performance of tested materials at different temperatures.

\section{Efficiency of DMs at Different Temperatures}

In order to compare the efficiency of tested materials at different temperatures, the obtained IML values were divided into four categories, which are presented in Table 1.
Table 1. Categories of DM efficiency (Bulevičius et al. 2014)

\begin{tabular}{|l|c|}
\hline \multicolumn{1}{|c|}{ Category of DM efficiency } & IML [\%] \\
\hline High efficiency & $>40$ \\
\hline Average efficiency & $20-40$ \\
\hline Low efficiency & $5-20$ \\
\hline Inefficient & $<5$ \\
\hline
\end{tabular}

The categories are also marked in the comparative charts (Fig. 6). The charts depict the dependence of IML on the time at different temperatures.

The analysis of the results shows that $\mathrm{CaCl}_{2}$ and $\mathrm{MgCl}_{2}$ can be attributed to the category of low DM efficiency at the temperature of $-20^{\circ} \mathrm{C}$. Both materials
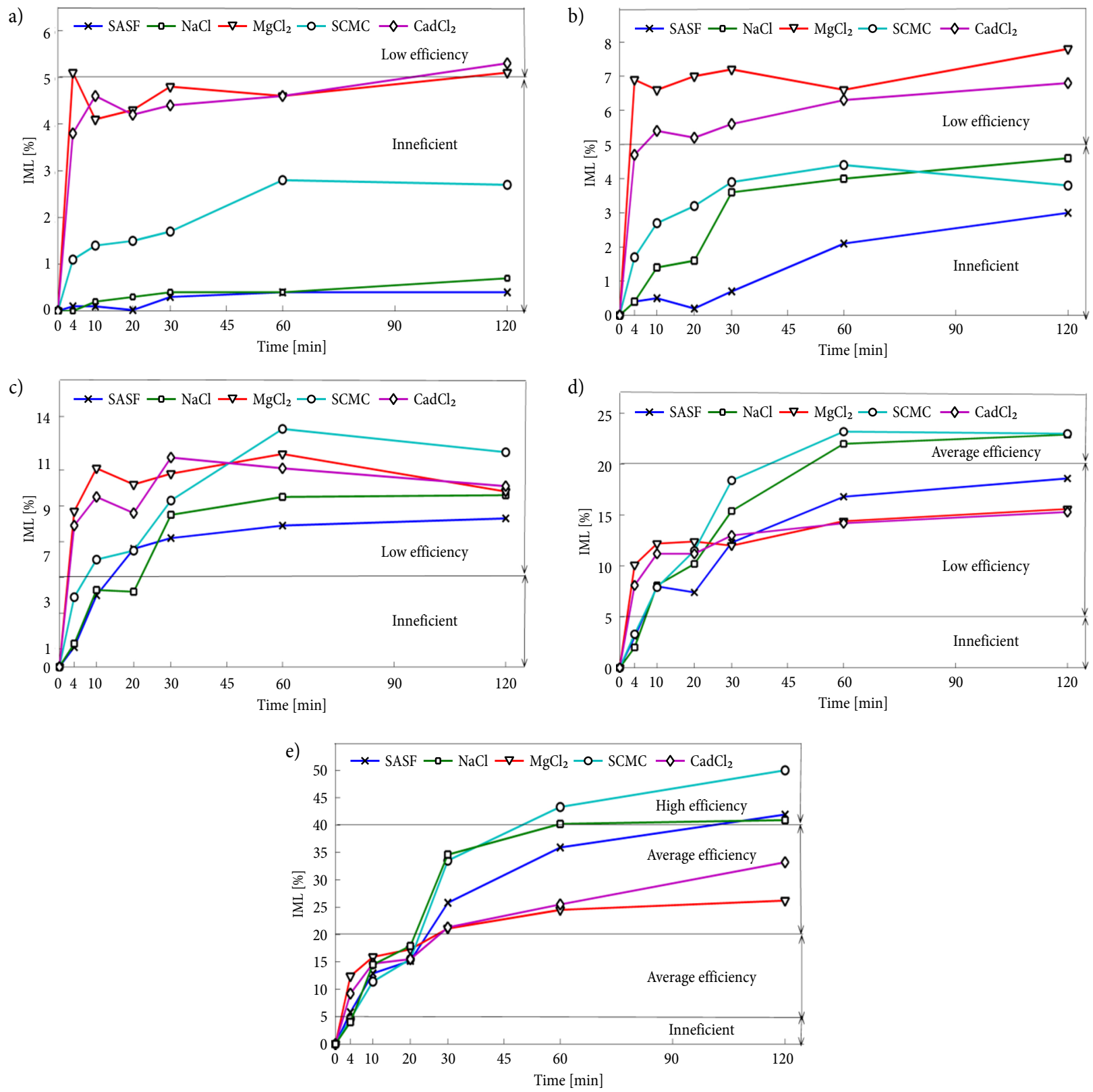

Fig. 6. Dependence of the efficiency of DMs on the ice melting time at different temperatures: $\mathrm{a}--20{ }^{\circ} \mathrm{C} ; \mathrm{b}--15{ }^{\circ} \mathrm{C} ; \mathrm{c}--9{ }^{\circ} \mathrm{C} ; \mathrm{d}--6{ }^{\circ} \mathrm{C}$; e $--3{ }^{\circ} \mathrm{C}$ 
reached the $5 \%$ solubility limit at the end of the test. However, $\mathrm{MgCl}_{2}$ exceeded this limit for a short period of time (up to $2 \mathrm{~min}$ ), $4 \mathrm{~min}$ after spreading the material. But then, this value was not exceeded until the end of the test. The remaining three $\mathrm{DMs}(\mathrm{NaCl}, \mathrm{SASF}$ and SCMC) were completely inefficient. SCMC reached its greatest value of $2.7 \%$ (the nearest to the $5 \%$ solubility limit) after $120 \mathrm{~min}$.

Only $\mathrm{CaCl}_{2}$ and $\mathrm{MgCl}_{2}$ can be attributed to the category of low DM efficiency when the temperature of ice is $-15{ }^{\circ} \mathrm{C}$. Both materials reached $5 \%$ solubility limit at the very beginning of the test, 4 min after spreading the material. The remaining three DMs did not reach this limit. Therefore, they can be considered completely inefficient. $\mathrm{NaCl}$ reached its greatest value of $4.6 \%$ (the nearest to the $5 \%$ solubility limit) after the maximum test time.

All of the tested materials reached only the lowefficiency limit when the temperature of ice was $-9^{\circ} \mathrm{C}$. SCMC, $\mathrm{CaCl}_{2}$ and $\mathrm{MgCl}_{2}$ exceed 10\% IML limit while the remaining two DMs $(\mathrm{NaCl}$ and SASF) did not exceed this value. SCMC reached the greatest IML value of $13.3 \%$ after $60 \mathrm{~min}$, although the value of $\mathrm{MgCl}_{2}$ was higher by $3.7 \%\left(\mathrm{MgCl}_{2}-10.2 \%\right.$; SCMC $\left.-6.5 \%\right)$ after $20 \mathrm{~min}$. The effect of all the DMs on the ice melting stabilized and even decreased after $60 \mathrm{~min}$.

Two materials SCMC and $\mathrm{NaCl}$, can be attributed to the category of average DM efficiency when the temperature of ice is $-6^{\circ} \mathrm{C}$. The values of average DM efficiency were respectively reached after 40 and $50 \mathrm{~min}$. SCMC reached the greatest IML value of $23.2 \%, 60 \mathrm{~min}$ after spreading of the material. The efficiency of the remaining three materials is low. However, the limit of low efficiency was reached at the very end of the test, after $4 \mathrm{~min}$. SASF reached its greatest value of $18.6 \%$ (the nearest to the $20 \%$ solubility limit), $120 \mathrm{~min}$ after spreading the material.

The three materials $\mathrm{NaCl}$, SCMC and SASF, can be attributed to the category of high DM efficiency at the temperature of $-3{ }^{\circ} \mathrm{C}$. SCMC reached the high-efficiency limit after $50 \mathrm{~min}$, the remaining two materials - at the end of the test, after $110 \mathrm{~min}$. SMC also reached the greatest IML value of $50 \%$. This value is $10 \%$ higher than the values of the remaining two materials, which reached the limit of $40 \%$. Of the remaining two materials, $\mathrm{CaCl}_{2}$ reached the greatest value of $33.2 \%$, which was the nearest to the limit of $40 \%$.

The Ice Melting Intensity (IMI) was additionally calculated in order to compare the efficiency and ability of the tested materials to effectively melt the ice. The following formula was applied:

$$
I M I=\frac{I M L_{n}-I M L_{n-1}}{t_{n}-t_{n-1}},
$$

where: $I M L_{n}$ - experimental IML time of estimated time [\%]; $I M L_{n-1}$ - the former value of IML time [min]; $t_{n}-n$-th calculated time value; $t_{n-1}-$ the former time value ( $n$-th-1) [min]. The results are presented in Table 2.

Four DM categories, presented in Table 3, were used to assess the results.
Table 2. IMI [\%/min]

\begin{tabular}{|c|c|c|c|c|c|c|}
\hline \multirow{2}{*}{$\mathrm{DM}$} & \multirow{2}{*}{$\begin{array}{l}\text { Duration of melting } \\
\text { action [min] }\end{array}$} & \multicolumn{5}{|c|}{ Temperature $\left[{ }^{\circ} \mathrm{C}\right]$} \\
\hline & & -20 & -15 & -9 & -6 & -3 \\
\hline \multirow{6}{*}{$\mathrm{NaCl}$} & 4 & 0 & 0.1 & 0.3 & 0.5 & 1.0 \\
\hline & 10 & 0 & 0.2 & 0.5 & 1.0 & 1.7 \\
\hline & 20 & 0 & 0 & 0 & 0.2 & 0.3 \\
\hline & 30 & 0 & 0.2 & 0.4 & 0.5 & 1.7 \\
\hline & 60 & 0 & 0 & 0 & 0.2 & 0.2 \\
\hline & 120 & 0 & 0 & 0 & 0 & 0 \\
\hline \multirow{6}{*}{$\mathrm{CaCl}_{2}$} & 4 & 0.9 & 1.2 & 2.0 & 2.0 & 2.3 \\
\hline & 10 & 0.1 & 0.1 & 0.3 & 0.5 & 0.9 \\
\hline & 20 & 0 & 0 & -0.1 & 0 & 0.1 \\
\hline & 30 & 0 & 0 & 0.3 & 0.2 & 0.6 \\
\hline & 60 & 0 & 0 & 0 & 0 & 0.1 \\
\hline & 120 & 0 & 0 & 0 & 0 & 0.1 \\
\hline \multirow{6}{*}{$\mathrm{MgCl}_{2}$} & 4 & 1.3 & 1.7 & 2.2 & 2.5 & 3.1 \\
\hline & 10 & -0.2 & -0.1 & 0.4 & 0.4 & 0.6 \\
\hline & 20 & 0 & 0 & -0.1 & 0 & 0.1 \\
\hline & 30 & 0.1 & 0 & 0.1 & 0 & 0.4 \\
\hline & 60 & 0 & 0 & 0 & 0.1 & 0.1 \\
\hline & 120 & 0 & 0 & 0 & 0 & 0 \\
\hline \multirow{6}{*}{ SCMC } & 4 & 0.3 & 0.4 & 1.0 & 0.8 & 1.1 \\
\hline & 10 & 0.1 & 0.2 & 0.4 & 0.8 & 1.1 \\
\hline & 20 & 0 & 0 & 0 & 0.4 & 0.4 \\
\hline & 30 & 0 & 0.1 & 0.3 & 0.7 & 1.8 \\
\hline & 60 & 0 & 0 & 0.1 & 0.2 & 0.3 \\
\hline & 120 & 0 & 0 & 0 & 0 & 0.1 \\
\hline \multirow{6}{*}{ SASF } & 4 & 0 & 0.1 & 0.3 & 0.7 & 1.4 \\
\hline & 10 & 0 & 0 & 0.5 & 0.8 & 1.2 \\
\hline & 20 & 0 & 0 & 0.3 & -0.1 & 0.2 \\
\hline & 30 & 0 & 0.1 & 0.1 & 0.5 & 1.1 \\
\hline & 60 & 0 & 0 & 0 & 0.2 & 0.3 \\
\hline & 120 & 0 & 0 & 0 & 0.0 & 0.1 \\
\hline
\end{tabular}

Table 3. Categories of IMI (Bulevičius et al. 2014)

\begin{tabular}{|l|c|}
\hline \multicolumn{1}{|c|}{ Category of IMI } & IMI [\%/min] \\
\hline High intensity & $>2$ \\
\hline Average intensity & $1-2$ \\
\hline Low intensity & $0.5-1$ \\
\hline Very low intensity & $<0.5$ \\
\hline
\end{tabular}

According to the calculated values of IMI, $\mathrm{CaCl}_{2}$ and $\mathrm{MgCl}_{2}$, they can be recognised as having the best properties to melt the ice fast. Of all the five materials, $\mathrm{CaCl}_{2}$ and $\mathrm{MgCl}_{2}$ had the highest IMI values at different test temperatures. These values were reached in $4 \mathrm{~min}$ after spreading the DMs. The highest values of these two materials ( 2.3 and $3.1 \% / \mathrm{min}$, respectively) were reached at the temperature of $-3{ }^{\circ} \mathrm{C}$. A decrease in temperature led to a decrease in these values. Thus, at the temperature of $-20^{\circ} \mathrm{C}$, the values of these materials were 0.9 and $1.3 \% / \mathrm{min}$, respectively. It can be concluded that both DMs used the highest ice melting potential at the beginning of the test, as the IMI values significantly 
decreased 10 min after spreading the material. The IMI values of other three materials ( $\mathrm{NaCl}$, SASF and SCMC) were lower than $2 \% / \mathrm{min}$; however, the values are rather constant (and correspond to the values of average melting intensity) up to $30 \mathrm{~min}$ of melting, except for the time interval between 10 and $20 \mathrm{~min}$. The obtained data show that the IMI values of all the materials significantly decreased in the time interval between 10 and $20 \mathrm{~min}$, which fully corresponds to the theoretical model (Fig. 2). After this time interval, a significant increase in these values was observed; however, after $30 \mathrm{~min}$, these values began to decrease again and approached the zero mark.

Summarizing the IML and IMI values, obtained from the laboratory tests, for all five tested DMs, the following four ice melting zones were distinguished:

1. intensive melting;

2. low melting;

3. average melting;

4. stabilized melting.

These zones were analysed in more detail in the theoretical part.

\section{Efficiency of DMs}

The efficiency of work is the ratio of the achieved result to the necessary costs. The current study aims to determine the price of $1 \%$ of melted ice when the same amount of a DM is spread over one square meter. Average market prices excluding VAT for all DMs tested in the year 2015 are provided in Table 4. All of the tested DMs were compared from the economic point of view, and the amount of salt spread over one square meter was calculated $\left(10 \mathrm{~g} / 0.0887 \mathrm{~m}^{2}=115 \mathrm{~g} / \mathrm{m}^{2}\right)$.

Table 4. Prices for all tested DMs in 2015

\begin{tabular}{|l|c|c|}
\hline \multicolumn{1}{|c|}{$\mathrm{DM}$} & Price of 1 tonne $[€]$ & Price of $115 \mathrm{~g} / \mathrm{m}^{2}\left[€ \cdot 10^{-3}\right]$ \\
\hline $\mathrm{NaCl}$ & 50 & 5.75 \\
\hline $\mathrm{CaCl}_{2}$ & 360 & 41.4 \\
\hline $\mathrm{MgCl}_{2}$ & 230 & 26.5 \\
\hline Icemelt & 263 & 30.3 \\
\hline Nordway & 1200 & 138 \\
\hline
\end{tabular}

The price was calculated for each material, necessary to melt $1 \%$ of ice, when it is affected by a DM for $120 \mathrm{~min}$. The following formula was applied:

$$
E=\frac{P_{\text {quad }}}{\mathrm{IML}}
$$

where: $P_{\text {quad }}-$ the price of the amount of the DM, which is necessary to melt $1 \mathrm{~m}^{2}$ of ice [€]; IML - ice mass loss [\%]. The calculated values are given in Table 5 .

It was found that $\mathrm{NaCl}$ is the most efficient ice melting material at temperatures below $-15{ }^{\circ} \mathrm{C}$. At higher temperatures, the most efficient $\mathrm{DM}$ is $\mathrm{MgCl}_{2}$. SASF melts the ice inefficiently in comparison with other DMs. When the temperatures of ice are $-9,-6$ and $-3{ }^{\circ} \mathrm{C}$, the differences in performance are 28,30 and 23 times, respectively, in comparison with the most efficient $\mathrm{DM}(\mathrm{NaCl})$.
Table 5. Price of one percent of melted ice, when it is affected by a DM for $120 \mathrm{~min}\left[€ \cdot 10^{-3}\right]$

\begin{tabular}{|l|c|c|c|c|c|}
\hline \multirow{2}{*}{$\mathrm{DM}$} & \multicolumn{5}{|c|}{ Temperature $\left[{ }^{\circ} \mathrm{C}\right]$} \\
\cline { 2 - 6 } & -20 & -15 & -9 & -6 & -3 \\
\hline $\mathrm{NaCl}$ & 8.21 & 1.25 & 0.60 & 0.25 & 0.14 \\
\hline $\mathrm{CaCl}_{2}$ & 7.81 & 6.09 & 4.10 & 2.71 & 1.25 \\
\hline $\mathrm{MgCl}_{2}$ & 5.19 & 3.39 & 2.70 & 1.70 & 1.01 \\
\hline SCMC & 11.2 & 7.96 & 2.52 & 1.32 & 0.60 \\
\hline SASF & 345 & 46 & 16.6 & 7.42 & 3.29 \\
\hline
\end{tabular}

\section{Conclusions}

The current paper studies the performance efficiency of five DMs using a laboratory ice melting test and determining the percentage of ice mass that is lost when different materials are applied at different temperatures. Having determined the values of IML and IMI for each tested DM at different temperatures and at different durations of melting action, it can be concluded that:

- All of the tested DMs dissolve the largest percentage of ice mass when taking the longest duration of melting action after spreading a DM. A decrease in ice temperature also leads to a decrease in IML values of all DMs, compared to the values at the highest temperature of $-3{ }^{\circ} \mathrm{C}$.

- Comparing the tested DMs by IML values, when the temperature of ice is up to $-9{ }^{\circ} \mathrm{C}$, SCMC melts the largest percentage of ice mass. However, at the lower ice temperatures, this material is attributed to the category of inefficient DMs. At low temperatures $(-20$ and $\left.-15{ }^{\circ} \mathrm{C}\right) \mathrm{MgCl}_{2}$ and $\mathrm{CaCl}_{2}$, respectively, melt the largest percentage of ice mass. The remaining three materials $(\mathrm{NaCl}, \mathrm{SASF}$ and SCMC) did not reach the $5 \%$ solubility limit and, therefore, could be considered completely inefficient.

- By IMI values, $\mathrm{CaCl}_{2}$ and $\mathrm{MgCl}_{2}$ are the most efficient DMs; however, they reach the highest IMI values in four min after spreading the material, rapidly exploiting the full potential of ice melting. A decrease in ice temperature leads to a decrease in IMI values of all the tested materials.

- The ice melting potential of all five tested DMs can be divided into four zones:

1. intensive melting (which lasts up to $10 \mathrm{~min}$ after Spreading a DM);

2. low melting (from 10 to $20 \mathrm{~min}$ );

3. average melting (from 20 to $60 \mathrm{~min}$ );

4. stabilized melting (from 60 to $120 \mathrm{~min}$ ).

- Comparing the tested DMs by the melting efficiency of $1 \%$ of ice, 120 min after spreading the same amount of a DM (115 g) over $1 \mathrm{~m}^{2}, \mathrm{NaCl}$ melts the ice most efficiently in up to $-15{ }^{\circ} \mathrm{C}$, and at the higher temperature, the most efficient is $\mathrm{MgCl}_{2}$. SASF is the most expensive ice melting material.

Laboratory ice melting test is a sufficiently reliable way to compare the performance efficiency of various DMs at different temperatures and different durations of melting action. This method, however, does not consider some important factors of ice-bound pavement: solar 
radiation, pavement temperature, wind speed and traffic intensity. In order to determine the possibilities of DMs to melt the ice and snow more precisely, it is necessary to carry out field tests under real conditions.

\section{References}

Akin, M.; Shi, X. 2012. Development of standard laboratory testing procedures to evaluate the performance of deicers, Journal of Testing and Evaluation 40(6): 1-12. http://doi.org/10.1520/JTE103615

Bulevičius, M.; Čygas, D.; Laurinavičius, A.; Mučinis, D.; Vaitkus, A. 2014. Materials and technologies for winter road maintenance in Lithuania, Routes/Roads 361: 60-67.

Burtwell, M. 2004. Deicing trials on UK roads: performance of prewetted salt spreading and dry salt spreading, in Six International Symposium on Snow Removal and Ice Control Technology, 7-9 June 2004, Washington, DC, US, 564-584.

Cuelho, E.; Harwood, J. 2012. Laboratory and field evaluation of anti-icing strategies, Transportation Research Record: Journal of the Transportation Research Board 2272: 144151. http://doi.org/10.3141/2272-17

Dai, H. L.; Zhang, K. L.; Xu, X. L.; Yu, H. Y. 2012. Evaluation on the effects of deicing chemicals on soil and water environment, Procedia - Environmental Sciences 13: 2122-2130. http://doi.org/10.1016/j.proenv.2012.01.201

Fay, L.; Shi, X. 2012. Environmental impacts of chemicals for snow and ice control: state of the knowledge, Water, Air, \& Soil Pollution 223(5): 2751-2770.

http://doi.org/10.1007/s11270-011-1064-6

Fay, L.; Shi, X. 2011. Laboratory investigation of performance and impacts of snow and ice control chemicals for winter road service, Journal of Cold Regions Engineering 25(3): 89114. http://doi.org/10.1061/(ASCE)CR.1943-5495.0000025

Fonnesbech, J. 2001. Ice control technology with 20 percent brine on highways, Transportation Research Record: Journal of the Transportation Research Board 1741: 54-59. http://doi.org/10.3141/1741-09

Fu, L.; Omer, R.; Jiang, C. 2012. Field test of organic deicers as prewetting and anti-icing agents for winter road maintenance, Transportation Research Record: Journal of the Transportation Research Board 2272: 130-135. http://doi.org/10.3141/2272-15

Fujimoto, A.; Tokunaga, R. A.; Kiriishi, M.; Kawabata, Y.; Takahashi, N.; Ishida, T.; Fukuhara, T. 2014. A road surface freezing model using heat, water and salt balance and its validation by field experiments, Cold Regions Science and Technology 106-107: 1-10. http://doi.org/10.1016/j.coldregions.2014.06.001

Ganjyal, G.; Fang, Q.; Hanna, M. A. 2007. Freezing points and small-scale deicing tests for salts of levulinic acid made from grain sorghum, Bioresource Technology 98(15): 28142818. http://doi.org/10.1016/j.biortech.2006.07.042

Giuliani, F.; Merusi, F.; Polacco, G.; Filippi, S.; Paci, M. 2012. Effectiveness of sodium chloride-based anti-icing filler in asphalt mixtures, Construction and Building Materials 30: 174-179. http://doi.org/10.1016/j.conbuildmat.2011.12.036

Hossain, S. M. K.; Fu, L.; Olesen, A. J. 2014. Effectiveness of anti-icing operations for snow and ice control of parking lots and sidewalks, Canadian Journal of Civil Engineering 41(6): 523-530. http://doi.org/10.1139/cjce-2013-0587

Kim, S. J.; Yethiraj, A. 2008. The effect of salt on the melting of ice: A molecular dynamics simulation study, The Journal of Chemical Physics 129(12): 1-7. http://doi.org/10.1063/1.2979247

Klein-Paste, A.; Potapova, J. 2014. Thermal aspects of melting ice with deicer chemicals, Transportation Research Record:
Journal of the Transportation Research Board 2440: 69-75. http://doi.org/10.3141/2440-09

Klein-Paste, A.; Wåhlin, J. 2013. Wet pavement anti-icing - a physical mechanism, Cold Regions Science and Technology 96: 1-7. http://doi.org/10.1016/j.coldregions.2013.09.002

Koefod, S.; Adkins, J; Akin, M. R. 2012. Alternative approaches to measuring deicer ice-melting capacity: optimization of test accuracy and precision, in Winter Maintenance and Surface Transportation Weather: International Conference on Winter Maintenance and Surface Transportation Weather, 30 April - 3 May 2012, Coralville, IA, 432-442.

Luker, C.; Rokosh, B.; Leggett, T. 2004. Laboratory melting performance comparison: rock salt with and without prewetting, in Six International Symposium on Snow Removal and Ice Control Technology, 7-9 June 2004, Washington, DC, US, 585-601.

Mauritis, M.; McGraw, J.; Jang, J. 1995. Method for determining ice undercut temperature of deicing chemicals, Journal of Materials in Civil Engineering 7(1): 84-86. http://doi.org/10.1061/(ASCE)0899-1561(1995)7:1(84)

Nixon, W. A.; Qiu, J.; Qiu, L.; Kochumman, G.; Xiong, J. 2005. Ice melting performance for ice-control chemicals, in TRB 84th Annual Meeting Compendium of Papers CD-ROM, 9-13 January 2005, Washington, DC, 1-21.

Ružinskas, A.; Sivilevičius, H. 2014. Influence of winter weather changes on road pavement condition in Lithuania, in The 9th International Conference "Environmental Engineering”: Selected Papers, 22-23 May 2014, Vilnius, Lithuania, 1-6. http://doi.org/10.3846/enviro.2014.167

Shi, X.; Fay, L.; Gallaway, C.; Volkening, K.; Peterson, M. M.; Pan, T.; Creighton, A.; Lawlor, C.; Mumma, S.; Liu, Y.; Nguyen, T. A. 2009. Evaluation of Alternative Anti-Icing and Deicing Compounds Using Sodium Chloride and Magnesium Chloride as Baseline Deicers - Phase I. Final Report No. CDOT-2009-1. Colorado Department of Transportation, DTD Applied Research And Innovation Branch. 294 p.

Shi, X.; Fortune, K.; Smithlin, R.; Akin, M.; Fay, L. 2013a. Exploring the performance and corrosivity of chloride deicer solutions: laboratory investigation and quantitative modeling, Cold Regions Science and Technology 86: 36-44. http://doi.org/10.1016/j.coldregions.2012.10.011

Shi, X.; Jungwirth, S.; Akin, M.; Wright, R.; Fay, L.; Veneziano, D.; Zhang, Y.; Gong, J.; Ye, Z. 2014. Evaluating snow and ice control chemicals for environmentally sustainable highway maintenance operations, Journal of Transportation Engineering 140(11): 05014005. http://doi.org/10.1061/(ASCE)TE.1943-5436.0000709

Shi, X.; O’Keefe, K. 2006. Anti-icing and pre-wetting: improved methods for winter highway maintenance in North America, in TRB 85th Annual Meeting Compendium of Papers CD-ROM, 22-26 January 2006, Washington, DC, 1-15.

Shi, X.; Veneziano, D.; Xie, N.; Gong, J. 2013b. Use of chloridebased ice control products for sustainable winter maintenance: a balanced perspective, Cold Regions Science and Technology 86: 104-112. http://doi.org/10.1016/j.coldregions.2012.11.001

SHRP H-205.1. Test Method for Ice Melting of Solid Deicing Chemicals.

Wang, H.; Zhao, J.; Chen, Z. 2008. Experimental investigation of ice and snow melting process on pavement utilizing geothermal tail water, Energy Conversion and Management 49(6): 1538-1546.

http://doi.org/10.1016/j.enconman.2007.12.008

Wåhlin, J.; Leisinger, S.; Klein-Paste, A. 2014. The effect of sodium chloride solution on the hardness of compacted snow, Cold Regions Science and Technology 102: 1-7. http://doi.org/10.1016/j.coldregions.2014.02.002 